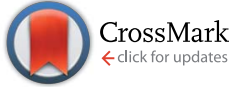

Cite this: RSC Adv., 2017, 7, 1480

Received 24th October 2016 Accepted 15th December 2016

DOI: $10.1039 / \mathrm{c} 6 \mathrm{ra} 25712 \mathrm{~g}$

www.rsc.org/advances

\section{Design, synthesis and antitubercular evaluation of benzothiazinones containing an oximido or amino nitrogen heterocycle moiety $\dagger$}

\begin{abstract}
Rui Zhang, $\ddagger^{a}$ Kai Lv, $t^{a}$ Bin Wang, ${ }^{b}$ Linhu Li, ${ }^{a}$ Bo Wang, ${ }^{a}$ Mingliang Liu, ${ }^{\text {ta }}$ Huiyuan Guo, ${ }^{a}$ Apeng Wang ${ }^{a}$ and $\mathrm{Yu} \mathrm{Lu}^{* \mathrm{~b}}$

A series of 8-nitro-6-(trifluoromethyl)-1,3-benzothiazin-4-ones (BTZs) bearing an oximido or amino nitrogen heterocycle moiety through modifications at the C-2 position of BTZ043 and BPTZ169 were designed and synthesized as new antitubercular agents. Many of the target compounds demonstrate excellent in vitro activity (MIC: $<0.016-0.088 \mu \mathrm{g} \mathrm{mL}^{-1}$ ) against the drug susceptive H37Rv strain and two clinically isolated multidrug-resistant Mycobacterium tuberculosis (MTB) strains. Compound 10a displays acceptable safety, aqueous solubility and pharmacokinetic properties, opening up a new possibility for further development.
\end{abstract}

Tuberculosis (TB), one of the world's major causes of illness and death, is caused mainly by Mycobacterium tuberculosis (MTB). ${ }^{1}$ The World Health Organization (WHO) estimated that approximately one third of the world population is infected with MTB, and 9.6 million people were infected and 1.5 million died from TB worldwide in $2014 .^{2}$ In particular, the spread of multidrugresistant (MDR) TB and the emergence of extensively drugresistant (XDR) TB have revitalized drug discovery efforts in search of novel drugs recently. ${ }^{3-5}$ It is encouraging that bedaquiline and delamanid have been approved for the treatment of MDR-TB, after a huge gap of over 40 years. ${ }^{6,7}$ However, there are only two new chemical entities, Q203 and TBA-354, in phase 1 clinical trials at present. Therefore, it is urgent to develop new anti-TB drugs. ${ }^{8,9}$

8-Nitro-6-(trifluoromethyl)-1,3-benzothiazin-4-ones (BTZs), a novel class of TB agents targeting DprE1, ${ }^{10-12}$ were reported to have potent activity in multiple models. ${ }^{13}$ BTZ043 (Fig. 1) and PBTZ169 (Fig. 1) are being studied preclinically. Compared with BTZ043, PBTZ169 is slightly more potent and not being stereoselective which makes it easier and cheaper to synthesize. ${ }^{\mathbf{1 4}}$ The structure-activity relationship (SAR) studies of BTZs show that $-\mathrm{CF}_{3}$ and $-\mathrm{NO}_{2}$ are the optimal groups at the C- 6 and $\mathrm{C}-8$

${ }^{a}$ Institute of Medicinal Biotechnology, Chinese Academy of Medical Sciences, Peking Union Medical College, Beijing 100050, China. E-mail: Imllyx@126.com; Tel: +86-10-63030965

${ }^{b}$ Beijing Key Laboratory of Drug Resistance Tuberculosis Research, Department of Pharmacology, Beijing Tuberculosis and Thoracic Tumor Research Institute, Beijing Chest Hospital, Capital Medical University, Beijing 101149, China. E-mail: luyu4876@hotmail.com; Tel: +86-10-89509357

$\dagger$ Electronic supplementary information (ESI) available. See DOI: $10.1039 / \mathrm{c} 6 \mathrm{ra} 25712 \mathrm{~g}$

\$ These authors contributed equally to this work. positions, respectively, so there is only one possible structural modifications at the $\mathrm{C}-2$ position.

On the other hand, some of fluoroquinolones (FQs), a class of important second-line anti-TB drugs, such as ciprofloxacin, ofloxacin and levofloxacin, are frequently used for management of TB including MDR-TB. ${ }^{15}$ Pyrrolidinyl, piperazinyl and piperidinyl are the most common groups at the C-7 position of FQs. It is interesting that recently the discovery of gemifloxacin and IMB-070593 highlights the importance of oxime-functionalized nitrogen heterocycles with respect to antibacterial activity. ${ }^{\mathbf{1 6 - 1 8}}$

Inspired by the above research results, we intended to replace the spiroketal moiety of BTZ043 with nitrogen cycloketone oximes and shift the terminal nitrogen on the piperazine ring of BPTZ169 outside the ring (Fig. 1), which were expected to explore SAR of BTZs though variations on the sizes of the heterocycle and the alkyl group of the oxime. Thus, a series of novel BTZ derivatives containing an oximido or amino nitrogen heterocycle moiety were designed and synthesized in this study. Our primary objective was to identify alternative groups at the
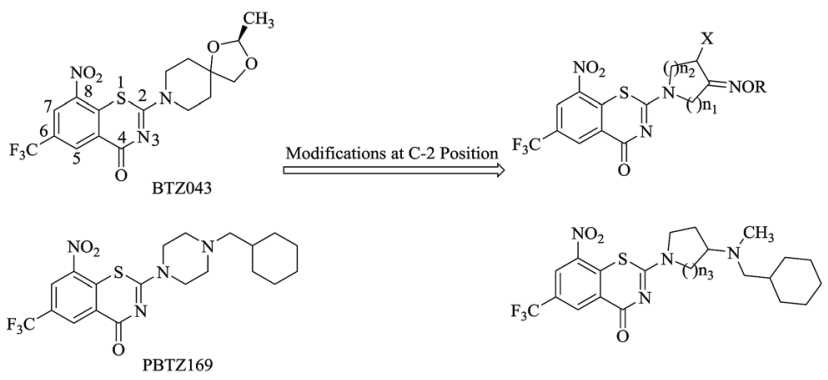

Fig. 1 Design of the new molecules. 


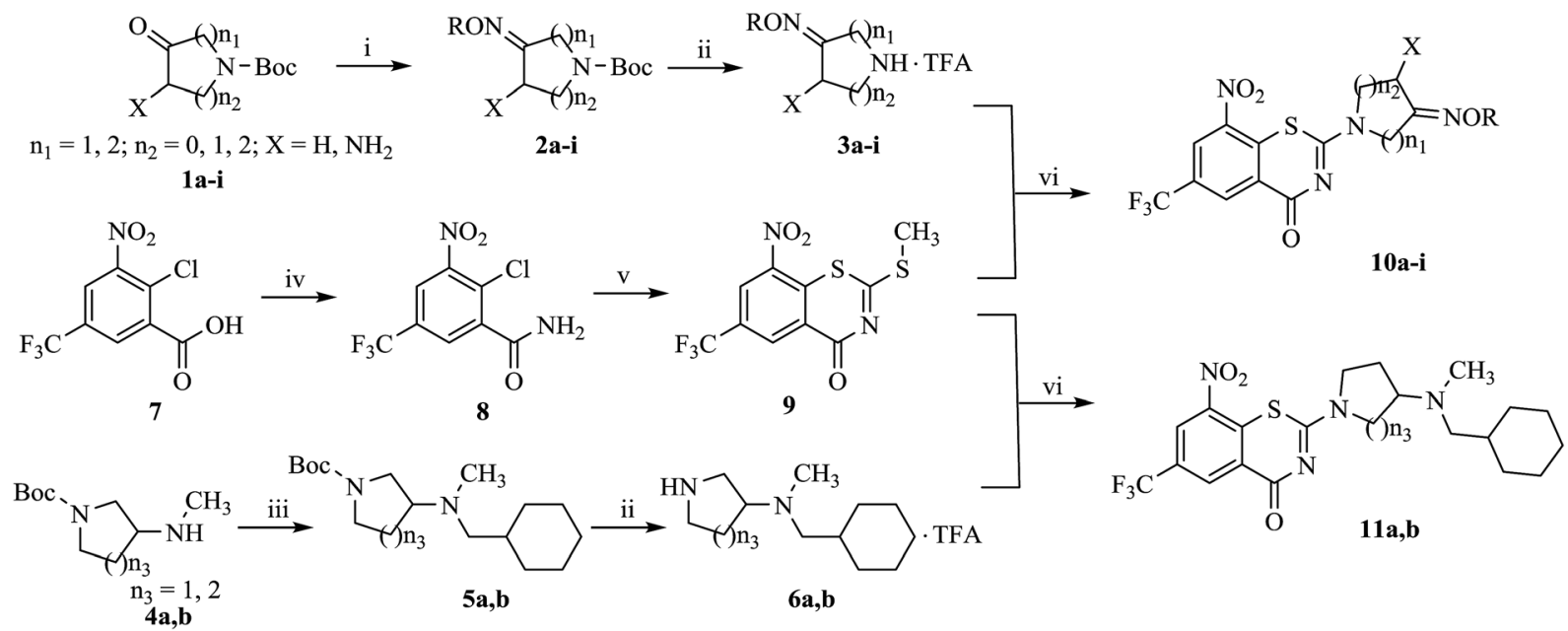

Scheme 1 Synthesis of target compounds $10 \mathrm{a}-\mathrm{i}$ and $11 \mathrm{a}, 1 \mathrm{~b}$. Reagents and conditions: (i) $\mathrm{RONH}_{2} \cdot \mathrm{HCl}_{2} \mathrm{~K}_{2} \mathrm{CO}_{3}, \mathrm{C}_{2} \mathrm{H}_{5} \mathrm{OH}, \mathrm{rt}, 40-65 \%$; (ii) TFA, $\mathrm{CH}_{2} \mathrm{Cl}_{2}$, rt, 50-52\%; (iii) c- $\mathrm{C}_{6} \mathrm{H}_{11} \mathrm{CH}_{2} \mathrm{Br}, \mathrm{K}_{2} \mathrm{CO}_{3}, \mathrm{DMF}, 80{ }^{\circ} \mathrm{C}, 50-52 \%$; (iv) $\mathrm{SOCl}_{2}, \mathrm{NH}_{3} \cdot \mathrm{H}_{2} \mathrm{O}$, reflux, 76\%; (v) $\mathrm{CS}_{2}, \mathrm{CH}_{3} \mathrm{l}, \mathrm{DMSO}, \mathrm{rt}, 41 \%$; (vi) $\left(\mathrm{C}_{2} \mathrm{H}_{5}\right)_{3} \mathrm{~N}$, $\mathrm{C}_{2} \mathrm{H}_{5} \mathrm{OH}, 60{ }^{\circ} \mathrm{C}, 45-59 \%$.

C-2 position of BTZs with potent antimycobacterial activity and facilitate the further development of BTZs.

Detailed synthetic pathways to novel BTZ derivatives 10a-i and 11a, 11b are outlined in Scheme 1. 4-7-Membered nitrogen cycloketones $1 \mathbf{a}-\mathbf{i}$ were smoothly converted to the oximes $\mathbf{2 a}$ by reaction with $O$-alkylhydroxyamines in ethanol at room temperature. The $N$-Boc protecting group on $\mathbf{2 a - i}$ was removed with trifluoroacetic acid (TFA) in dichloromethane to afford the nitrogen cycloketone oximes $3 \mathbf{a}-\mathbf{i}$ in $40-65 \%$ yield.

Compounds 6a, 6b were easily prepared from the corresponding tert-butyl 3-(methylamino) pyrrolidine/piperidine-1carboxylate 4a, $\mathbf{4 b}$ via nucleophilic substitution reaction with (bromomethyl)cyclohexane in the presence of $\mathrm{K}_{2} \mathrm{CO}_{3}$ in dimethyl formamide (DMF) at $80{ }^{\circ} \mathrm{C}$, and then the resulting cyclohexylmethylates $\mathbf{2 a}, \mathbf{2 b}$ were treated with TFA.

Amidation of 2-chloro-3-nitro-5-(trifluoromethyl) benzoic acid 7 gave amide 8, which was condensated with carbon disulfide and methyl iodide yielded BTZ core compound $9 .^{10}$ Derivatives 10a-i and 11a, 11b were conveniently obtained from $\mathbf{9}$ by nucleophilic substitution with side chain compounds $\mathbf{3 a}-\mathbf{i}$ and $\mathbf{6 a}, \mathbf{6 b}$, respectively.

The synthesized compounds 10a-i and 11a, 11b were preliminarily screened for in vitro activity against MTB H37Rv ATCC 27294 strain, using the Microplate Alamar Blue Assay (MABA). ${ }^{19}$ The minimum inhibitory concentration (MIC) is defined as the lowest concentration effecting a reduction in fluorescence of $>90 \%$ relative to the mean of replicate bacterium-only controls. The minimum inhibitory concentration (MIC) values of the compounds along with PBTZ169, isoniazid (INH) and rifampicin (RFP) for comparison are presented in Table 1.

The data reveal that with a few exceptions (10d, 10f, 10i), all of the BTZ derivatives have potent in vitro activity against this strain (MIC: $<0.1 \mu \mathrm{g} \mathrm{mL}^{-1}$ ), which is better than BPTZ169 (MIC: $\left.0.116 \mu \mathrm{g} \mathrm{mL}^{-1}\right)$. In particular, the most active compounds $\mathbf{1 0 b}$, 10c and 10g (MIC: $<0.016 \mu \mathrm{g} \mathrm{mL}{ }^{-1}$ ) were found to be $>3->7$ fold more potent than BPTZ169, INH and RFP (MIC: 0.049-0.116 $\left.\mu \mathrm{g} \mathrm{mL}^{-1}\right)$. The potency of the oxime BTZ derivatives (10a-h) in this study is related to both of the sizes of the heterocycle and alkyl group (R). Generally, 4- and 6-membered heterocycles show the best activity, followed by 7 - and 5 -membered ones with the same R group $\left(\mathrm{CH}_{3}\right)$ successively (10a $v s .10 \mathrm{~d} v s$. 10e $v s$. 10h). Moreover, the contribution of the alkyl groups of the oxime moiety to the activity is relevant to the heterocycles. The activity of the $\mathrm{R}$ groups is as follows: benzyl = ethyl > methyl for azetidyl-based BTZs (10a vs. 10b vs. 10c), and but benzyl > methyl $\gg$ ethyl for piperidinyl-based ones (10e vs. 10f $v s .10 \mathrm{~g})$. Further investigation also suggests that introduction of an amino group on the heterocycles is detrimental. For instance, 3amino-4-(methoxyimino)piperidin-1-yl derivative (10i) displays MIC value of $0.436 \mu \mathrm{g} \mathrm{mL} \mathrm{mL}^{-1}$ which is 15 -fold less potent than 10e (MIC: $0.029 \mu \mathrm{g} \mathrm{mL} \mathrm{m}^{-1}$ ).

On the other hand, when the nitrogen atom of the piperazine ring of PBTZ169 was converted to an exocyclic tertiary amino group, the resulting compound 11a demonstrates increased activity (MIC: $0.051 \mu \mathrm{g} \mathrm{mL} \mathrm{m}^{-1}$ ). It is clear that the piperidin-1-yl group (11a) could be displaced by a pyrrolidin-1-yl moiety (11b) without obviously affecting the potency. These results indicate that 4 -aminopiperidine and 3 -aminopyrrolidine rings are preferred over piperazine.

The compounds 10a-i and 11a, 11b were examined for toxicity $\left(\mathrm{CC}_{50}\right)$ in human lung adenoma A549 cell lines by MTT assay and the results are reported in Table 1 . All of them $\left(\mathrm{CC}_{50}\right.$ : 57.66-707.33 $\left.\mu \mathrm{g} \mathrm{mL}^{-1}\right)$ are more cytotoxic than PBTZ169 $\left(\mathrm{CC}_{50}\right.$ : $784.20 \mu \mathrm{g} \mathrm{mL}^{-1}$ ), but the selectivity index (SI: 7667->44 208) of compounds 10b, 10c, 10g, 11a and 11b are bigger than PBTZ169 (SI: 6760) for MTB H37Rv ATCC 27294.

Encouraged by their strong potency against the drugsensitive MTB H37Rv strain, these BTZ derivatives except compounds 10d, 10f and 10i were further evaluated against two clinical isolated MDR-MTB strains 16892 (resistant to both of INH and RFP) and 16802 (resistant to INH, RFP, 
Table 1 Structures and in vitro activity of 10a-i and 11a, 11b against MTB H37Rv ATCC $2729^{a}$

10e

${ }^{a}$ MTB H37Rv ATCC 2729 was acquired from ATCC. ${ }^{b} \mathrm{CC}_{50}: 50 \%$ cytotoxic concentration. ${ }^{c}$ SI: selectivity index for MTB H37Rv ATCC 27294, CC $_{50}$ /MIC; INH: isoniazid: RFP: rifampicin.

streptomycin, ethambutol and levofloxacin) (Table 2). The results indicate that all of 10a-c, 10e, 10g, 10h and 11a, 11b have excellent activity against both of the two strains with similar MIC values $\left(0.016-0.031 \mu \mathrm{g} \mathrm{mL}^{-1}\right.$ ) to PBTZ169 (MIC: $0.016 \mu \mathrm{g} \mathrm{mL}{ }^{-1}$ ), suggesting their promising potential for both drug-sensitive (MIC: $<0.1 \mu \mathrm{g} \mathrm{mL} \mathrm{m}^{-1}$ ) and resistant MTB strains (Tables 1 and 2).

The BTZ derivatives were initially evaluated for their water solubility which was determined by HPLC measurement of the concentration of a micromembrane filtered saturated solution..$^{18}$ Compared with other oxime derivatives $(0.02-0.05 \mathrm{mg}$ $\left.\mathrm{mL}^{-1}, \operatorname{clog} P: 3.28-4.98\right)$, compound 10a (clog $\left.P: 2.83\right)$ has much
Table 2 In vitro activity against MDR-MTB strains, solubility and metabolic stability of selected compounds ${ }^{a}$

\begin{tabular}{|c|c|c|c|c|}
\hline \multirow[b]{2}{*}{ Compd } & \multicolumn{2}{|c|}{$\operatorname{MIC}\left(\mu \mathrm{g} \mathrm{mL}^{-1}\right)$} & \multirow[b]{2}{*}{$\begin{array}{l}\text { Water Solubility } \\
\left(\mathrm{mg} \mathrm{mL}^{-1}\right)\end{array}$} & \multirow[b]{2}{*}{$\begin{array}{l}\text { Metabolic stability } \\
t_{1 / 2}(\min )\end{array}$} \\
\hline & $\begin{array}{l}\text { MDR-MTB } \\
16892^{b}\end{array}$ & $\begin{array}{l}\text { MDR-MTB } \\
16802^{b}\end{array}$ & & \\
\hline $10 \mathrm{a}$ & 0.016 & 0.031 & 0.24 & $>120$ \\
\hline $10 \mathrm{~b}$ & 0.016 & 0.016 & 0.03 & NT \\
\hline $10 \mathrm{c}$ & 0.016 & 0.016 & 0.05 & NT \\
\hline $10 \mathrm{e}$ & 0.016 & 0.016 & 0.02 & NT \\
\hline $10 \mathrm{~g}$ & 0.016 & 0.016 & 0.05 & NT \\
\hline $10 \mathrm{~h}$ & 0.031 & 0.016 & 0.03 & NT \\
\hline $11 \mathrm{a}$ & 0.016 & 0.016 & 4.05 & 49.1 \\
\hline $11 b$ & 0.016 & 0.016 & 3.11 & 24.3 \\
\hline PBTZ169 & 0.016 & 0.016 & 0.30 & 19.5 \\
\hline INH & $>40$ & 2.5 & NT & NT \\
\hline RFP & $>40$ & 20 & NT & NT \\
\hline
\end{tabular}

${ }^{a}$ NT: not tested. ${ }^{b}$ MDR-MTB 16892 and MDR-MTB 16802 were isolated from patients in Beijing Chest Hospital.

Table 3 PK Profiles of 10a, 11a and 11b dosed orally in mice ${ }^{a}$ at $50 \mathrm{mg}$ $\mathrm{kg}^{-1}(n=3)$

\begin{tabular}{|c|c|c|c|c|}
\hline Compd & $10 a$ & 11a & 11b & PBTZ169 \\
\hline $\begin{array}{l}C_{\max } \\
\left(\mathrm{ng} \mathrm{mL}^{-1}\right)\end{array}$ & $5767 \pm 3190$ & $173 \pm 76.8$ & $327 \pm 137$ & $1512 \pm 696$ \\
\hline$T_{\max }(\mathrm{h})$ & $0.333 \pm 0.144$ & $1.000 \pm 0.866$ & $0.250 \pm 0$ & $0.583 \pm 0.382$ \\
\hline $\begin{array}{l}\mathrm{AUC}_{0-\infty} \\
\left(\mathrm{h} \mathrm{ng} \mathrm{mL} \mathrm{mL}^{-1}\right)\end{array}$ & $7678 \pm 4395$ & $627 \pm \mathrm{ND}$ & $646 \pm 460$ & $5681 \pm 1756$ \\
\hline$t_{1 / 2}(\mathrm{~h})$ & 1.15 & $1.76 \pm \mathrm{ND}$ & $1.69 \pm 0.483$ & $3.31 \pm 0.187$ \\
\hline MRT (h) & $1.85 \pm 0.634$ & $2.92 \pm \mathrm{ND}$ & $2.42 \pm 0.171$ & $4.48 \pm 0.484$ \\
\hline
\end{tabular}

${ }^{a}$ Male CD-1 mice was acquired from WuXi AppTec (Shanghai) CO., Ltd; ND: not determined (parameters not determined due to inadequately defined terminal elimination phase).

greater solubility $\left(0.24 \mathrm{mg} \mathrm{mL}^{-1}\right)$ which is only slightly smaller than PBTZ169 $\left(0.30 \mathrm{mg} \mathrm{mL}^{-1}\right)$. As expected, exocyclic tertiary amino derivatives 11a, 11b possess excellent aqueous solubility (3.11-4.05 $\mathrm{mg} \mathrm{mL}^{-1}$ ) which is more than ten times that of BPTZ169 (Table 2). Moreover, all of 10a, 11a and 11b show better metabolic stability $\left(t_{1 / 2}: 24.3->120 \mathrm{~min}\right)$ in human liver microsomes compared to BPTZ169 $\left(t_{1 / 2}: 19.5 \mathrm{~min}\right)$.

Based on the measured activity levels against the tested strains, solubility and metabolic stability, 10a, 11a and $\mathbf{1 1} \mathbf{b}$ were further tested for in vivo pharmacokinetic (PK) profiles in mice after a single oral administration of $50 \mathrm{mg} \mathrm{kg}^{-1}$. As shown in Table 3, compound 10a, with a 3-(methoxyimino) azetidine moiety, displays good PK properties, with $C_{\max }$ of $5767 \mathrm{ng} \mathrm{mL}^{-1}$, $\mathrm{AUC}_{0-\infty}$ of $7678 \mathrm{~h} \mathrm{ng} \mathrm{mL}^{-1}$ and $t_{1 / 2}$ of $1.15 \mathrm{~h}$. Compounds 11a and 11b have a relatively longer $t_{1 / 2}$ of $1.69-1.76 \mathrm{~h}$ and MRT of 2.42-2.92 h, but a poor $C_{\max }$ of $173-327 \mathrm{ng} \mathrm{mL}^{-1}$ and $\mathrm{AUC}_{0-\infty}$ of 627-646 h ng mL ${ }^{-1}$. Unexpectedly, all of the three compounds have a shorter $t_{1 / 2}$ of $1.15-1.76 \mathrm{~h}$ compared to BPTZ169 $\left(t_{1 / 2}: 3.31\right.$ h). The in vitro and in vivo half-times of inconsistency may be due to differences in species between human liver microsomes and mice. 


\section{Conclusions}

A series of novel BTZ derivatives bearing an oximido or amino nitrogen heterocycle moiety were designed as new antitubercular agents through modifications at the C-2 position of BTZ043 and BPTZ169. Many of them exhibit excellent in vitro inhibitory activity against both drug-sensitive MTB strain $\mathrm{H} 37 \mathrm{Rv}$ and drug-resistant clinical isolates. Compound 10a displays acceptable safety, aqueous solubility and PK properties, and it may serve as a new and promising lead compound for further antitubercular drug discovery. Studies to determine the in vivo efficacy of $\mathbf{1 0 a}$ are currently underway.

\section{Ethical statement}

Animals were maintained in accordance with the guidelines of the Chinese Association for Laboratory Animal Sciences, Beijing, China, and approved by the Institutional Ethical Committee (IEC) of Peking Union Medical College.

\section{Acknowledgements}

This work is supported by the National S\&T Major Special Project on Major New Drug Innovations (2014ZX09507009-003, 2015ZX09102007-008), NSFC (81502923, 81373267, 21502237) and Beijing Municipal Administration of Hospitals Clinical Medicine Development of Special Funding Support (ZYLX201304).

\section{Notes and references}

1 A. Nusrath Unissa, L. E. Hanna and S. Swaminathan, Chem. Biol. Drug Des., 2016, 87, 537-550.

2 L. Anderson, A. Dean and D. Falzon, et al., Global tuberculosis report, World Health Organization, Geneva, 20th edn, 2015.

3 D. Schraufnagel and J. Abubaker, JAMA, J. Am. Med. Assoc., 2000, 283, 54-55.

4 D. Jones, Nat. Rev. Drug Discovery, 2013, 12, 175-176.

5 D. T. Hoagland, J. Liu, R. B. Lee and R. E. Lee, Adv. Drug Delivery Rev., 2016, 102, 55-72.

6 J. Cohen, Science, 2013, 339, 130.

7 N. J. Ryan and J. H. Lo, Drugs, 2014, 74, 1041-1045.

8 Z. Ma, C. Lienhardt, H. McIlleron, A. J. Nunn and X. Wang, Lancet, 2010, 375, 2100-2109.

9 B. Villemagne, C. Crauste, M. Flipo, A. R. Baulard, B. Deprez and N. Willand, Eur. J. Med. Chem., 2012, 51, 1-16.
10 J. Neres, F. Pojer, E. Molteni, L. R. Chiarelli, N. Dhar, S. BoyRottger, S. Buroni, E. Fullam, G. Degiacomi, A. P. Lucarelli, R. J. Read, G. Zanoni, D. E. Edmondson, E. De Rossi, M. R. Pasca, J. D. McKinney, P. J. Dyson, G. Riccardi, A. Mattevi, S. T. Cole and C. Binda, Sci. Transl. Med., 2012, 4, 150 ra121.

11 C. Trefzer, M. Rengifo-Gonzalez, M. J. Hinner, P. Schneider, V. Makarov, S. T. Cole and K. Johnsson, J. Am. Chem. Soc., 2010, 132, 13663-13665.

12 A. L. Ribeiro, G. Degiacomi, F. Ewann, S. Buroni, M. L. Incandela, L. R. Chiarelli, G. Mori, J. Kim, M. Contreras-Dominguez, Y. S. Park, S. J. Han, P. Brodin, G. Valentini, M. Rizzi, G. Riccardi and M. R. Pasca, PLoS One, 2011, 6, e26675.

13 V. Makarov, G. Manina, K. Mikusova, U. Mollmann, O. Ryabova, B. Saint-Joanis, N. Dhar, M. R. Pasca, S. Buroni, A. P. Lucarelli, A. Milano, E. De Rossi, M. Belanova, A. Bobovska, P. Dianiskova, J. Kordulakova, C. Sala, E. Fullam, P. Schneider, J. D. McKinney, P. Brodin, T. Christophe, S. Waddell, P. Butcher, J. Albrethsen, I. Rosenkrands, R. Brosch, V. Nandi, S. Bharath, S. Gaonkar, R. K. Shandil, V. Balasubramanian, T. Balganesh, S. Tyagi, J. Grosset, G. Riccardi and S. T. Cole, Science, 2009, 324, 801-804.

14 V. Makarov, B. Lechartier, M. Zhang, J. Neres, A. M. van der Sar, S. A. Raadsen, R. C. Hartkoorn, O. B. Ryabova, A. Vocat, L. A. Decosterd, N. Widmer, T. Buclin, W. Bitter, K. Andries, F. Pojer, P. J. Dyson and S. T. Cole, EMBO Mol. Med., 2014, 6, 372-383.

15 J. Huang, M. Wang, B. Wang, Z. Wu, M. Liu, L. Feng, J. Zhang, X. Li, Y. Yang and Y. Lu, Bioorg. Med. Chem. Lett., 2016, 26, 2262-2267.

16 K. Lv, M. L. Liu, L. S. Feng, L. Y. Sun, Y. X. Sun, Z. Q. Wei and H. Q. Guo, Eur. J. Med. Chem., 2012, 47, 619-625.

17 C. Y. Hong, Y. K. Kim, J. H. Chang, S. H. Kim, H. Choi, D. H. Nam, Y. Z. Kim and J. H. Kwak, J. Med. Chem., 1997, 40, 3584-3593.

18 T. Zhang, W. Shen, M. Liu, R. Zhang, M. Wang, L. Li, B. Wang, H. Guo and Y. Lu, Eur. J. Med. Chem., 2015, 104, 73-85.

19 Y. Lu, M. Zheng, B. Wang, L. Fu, W. Zhao, P. Li, J. Xu, H. Zhu, H. Jin, D. Yin, H. Huang, A. M. Upton and Z. Ma, Antimicrob. Agents Chemother., 2011, 55, 5185-5193. 